\title{
Influencia homérica en el Banquete de Filóxeno
}

\author{
M. ${ }^{a}$ Teresa Amado Rodríguez \\ Universidad de Santiago de Compostela \\ mariateresa.amado@usc.es
}

Homeric Influence on the Banquet of Philoxenus

\begin{abstract}
En este trabajo se estudian las relaciones transtextuales del poema gastronómico de Filóxeno con la poesía homérica, buscando los elementos lingüísticos y literarios que proceden de la épica. La relación con el texto homérico permite arrojar luz sobre uno de los pasajes más oscuros del Banquete.

Palabras clave: Filóxeno; Homero; poesía gastronómica; transtextualidad..
\end{abstract}

In this paper we study the transtextual relations of the gastronomic poem by Philoxenus with Homeric poetry, searching for the linguistic and literary elements that come from epic poetry. The connection with the Homeric text allows us to shed light on one of the darkest passages of The Banquet.

Key words: Philoxenus; Homer; gastronomic poetry; transtextuality.

\section{INTRODUCCIÓN}

A mediados del siglo V a.C., cuando Atenas alcanza su máximo esplendor y se abre al mundo, importando nuevos productos que van a cambiar sus parcas costumbres alimentarias, nace en Grecia la literatura gastronómica, con manifestaciones en prosa, sobre todo libros de cocina, y en verso. Nuestro conocimiento de los prosistas no pasa de un listado de nombres y títulos, pero de la producción poética conservamos alrededor de quinientos versos, todos transmitidos por Ateneo de Náucratis, pertenecientes a tres poetas: Arquéstrato de Gela, Matrón de Pítane y Filóxeno. El primero de ellos

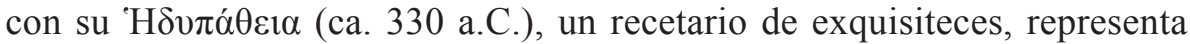
el espíritu preceptista y didáctico de la poesía gastronómica, mientras que

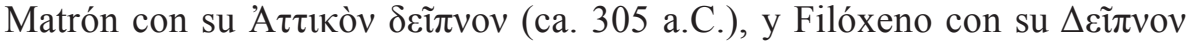
(ca. 390 a.C.), se encuadran en la línea descriptiva, ofreciendo una relación pormenorizada de platos y rituales de un banquete suntuoso con la única intención de divertir. 
Considerados como un género menor y víctimas de prejuicios ya desde la antigüedad, estos textos han suscitado poco interés entre los estudiosos, quienes además suelen centrar su atención en el contenido, como fuente de información para la historia de la gastronomía, más que en la dimensión literaria y filológica de los mismos. Esta afirmación es especialmente cierta en el caso de Filóxeno, sobre el cual hasta este momento poco más se ha estudiado que lo que Degani 1998, p. 94, llama Philoxenosfrage, es decir, los problemas sobre la identidad del autor, que, partiendo de la confusión de los propios

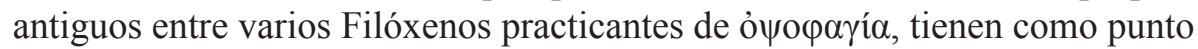
central de discusión el fr.189 K-A del cómico Platón ${ }^{1}$. En este desinterés puede influir el estado del texto, bastante lamentable en algunos puntos, con lagunas insalvables y pasajes corruptos de imposible reconstrucción, imputables en buena medida a errores de los copistas tardíos de Ateneo, por sus serias dificultades para comprender términos alambicados y alusiones oscuras. Una buena edición crítica con comentario, al estilo de las que se hicieron de los otros poetas gastronómicos (Olson y Sens 1999 y 2000), sería la base necesaria para cualquier otro estudio ${ }^{2}$.

Cualquiera que sea el punto de vista desde el que abordemos el texto de Filóxeno, es imprescindible tener presentes a los otros dos poetas gastronómicos, sobre todo a Matrón por identidad de tema y enfoque. Sin embargo las diferencias entre ambos Banquetes son evidentes: metro heroico, dialecto jónico-épico, estilo homerizante en el de Pítane, metro lírico, lengua doria y estilo ditirámbico en Filóxeno. Las características del texto matroniano se deben a sus procedimientos compositivos, ya que elabora un auténtico $\mathrm{Mo}$ saikarbeit, rehaciendo y combinando versos homéricos casi como si se trata-

${ }^{1}$ El Banquete se ha atribuido a Filóxeno de Citera, de Léucade o incluso a un tercer Filóxeno amante de la buena gastronomía. Sutton 1989 es la única editora que tiene al de Citera como autor. Una discusión de teorías en Dalby 1994, pp. 269-73.

2 Ambas ediciones, además de a aspectos de contenido, atienden a todo tipo de cuestiones del texto y sitúan a los autores en la tradición literaria a la que pertenecen. En el caso de Arquéstrato la reciente $2^{\mathrm{a}}$ edición de Wilkins y Hill 2011, siendo útil para estudiosos de la gastronomía, no sustituye a la de Olson y Sens 2000 en cuestiones más filológicas y literarias. El texto de Filóxeno sólo está editado en diversas antologías de poetas, en el mejor de los casos con un exiguo aparato crítico y alguna nota. A pesar de que la edición considerada canónica sigue siendo la de Page 1962, para el presente trabajo seguimos la más reciente de Campbell 1993, pp. 180-197, respetuosa con la tradición, pero más comprometida en la interpretación de pasajes corruptos y oscuros. Ello no nos excusa de hacer referencias puntuales a otras cuando las variantes afectan a la interpretación del texto citado. 
se de un centón (Salvioni 1979-80, p. 24). Filóxeno, sin embargo, destaca por el rebuscamiento estilístico y la originalidad en la expresión, esforzándose sobre todo en aquello que Aristóteles consideró seña de identidad del ditirambo: el uso de términos compuestos ${ }^{3}$. Pero, con todo, la huella homérica está presente en forma de imitación del estilo, empleo de tópicos e ideas, reproducción de sintagmas homéricos más o menos alterados o de alusiones veladas que pueden ayudarnos a aclarar el sentido de pasajes de difícil interpretación, desde luego en un porcentaje infinitamente menor que en Matrón y a veces de manera más sutil. Analizaremos a continuación esas huellas de transtextualidad ${ }^{4}$.

\section{El estilo catalógico}

\section{Las fórmulas introductorias}

En el Banquete de Filóxeno, uno de los comensales enumera la larga lista de platos que tuvo ocasión de disfrutar. Su identidad es desconocida, igual que la de su único interlocutor, a quien le une estrecha relación de amistad, según se deduce de la manera de dirigirse a él: pí $\lambda \varepsilon$ (836 b 16), la más común de las fórmulas de tratamiento amistoso en singular, y $\varphi \imath \lambda o ́ \tau \alpha \varsigma$ (836 b 7 y 35), mucho menos frecuente y sin documentación anterior al s. IV a.C. (Dickey 1996, pp. 134-135, 138). Estamos ante un verdadero catálogo de exquisiteces elaborado con la técnica acumulativa de la épica, en el cual la suma de elementos es unas veces funcional y otras meramente ornamental. Los dos grandes catálogos del texto homérico, posibles modelos y fuente de inspiración para Filóxeno, están planteados de diferente manera. El de las naves de Ilíada podríamos decir que es estático, porque no contempla desplazamiento de los elementos enumerados; el de la vékvıı de Odisea es dinámico, pues se dispone como un cortejo de almas, que se acercan a Odiseo mientras se aplica al ritual de evocación. Dos son las fórmulas usadas por Homero para presentar a los moradores del Hades: una con el verbo $\tilde{\hat{\eta}} \lambda \theta \varepsilon$ para los personajes de su entorno fa-

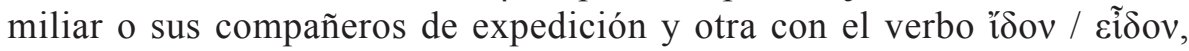

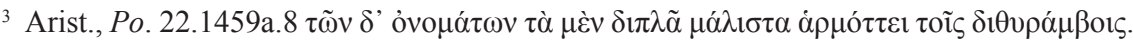

${ }^{4}$ Empleamos el término 'transtextualidad' en el sentido amplio en que lo hace Genette 1989, pp. 9-17, incluyendo todo tipo de relaciones de dependencia entre dos textos. 
que es la favorita en el catálogo de las heroínas para singularizar a las

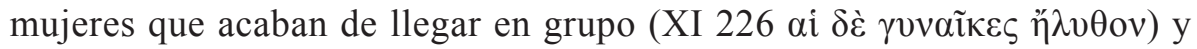
para los últimos difuntos del catálogo, ajenos ya a la guerra de Troya y a la trayectoria vital de Odiseo.

\begin{tabular}{|c|c|}
\hline$\tilde{\mathfrak{\eta}} \lambda \theta \varepsilon$ & ífov / عĩ்ov \\
\hline 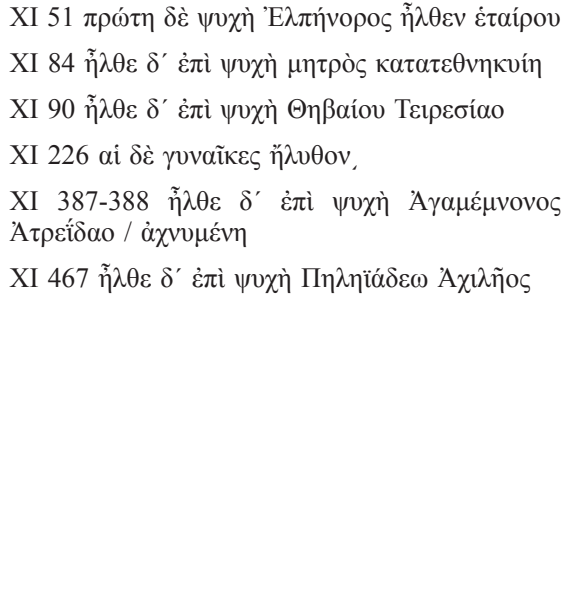 & 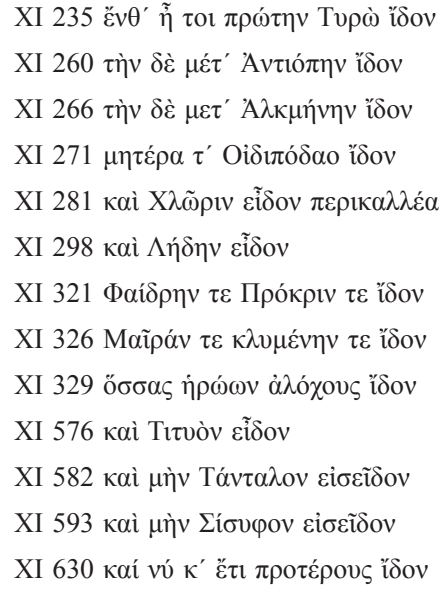 \\
\hline
\end{tabular}

Filóxeno adopta este modelo dinámico e introduce las viandas y otros elementos y utensilios de este peculiar desfile también de dos maneras diferentes: unas veces llegan y otras las llevan, aunque no podemos hablar de verdaderas fórmulas en el sentido estricto del término:

\begin{tabular}{|c|c|}
\hline$\ddot{\eta} \lambda v \theta \varepsilon$ y compuestos & 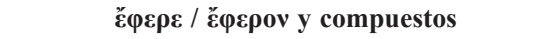 \\
\hline 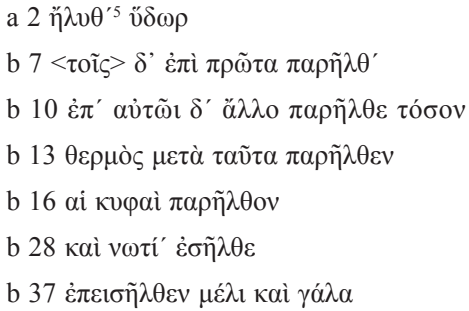 & 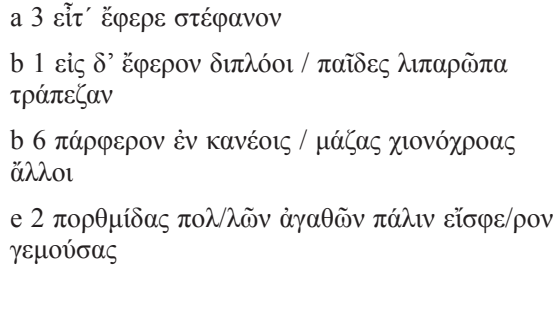 \\
\hline
\end{tabular}

5 Page 1962 conjetura $\ddot{\eta} \lambda \theta^{\prime}$ '. 
El uso de $\ddot{\eta} \lambda v \theta \varepsilon$ / $\ddot{\eta} \lambda v \theta$ ov o algunos de sus compuestos, pese a no ajustarse a la literalidad de la fórmula homérica, haría que el público la evocase inmediatamente, produciendo además un fuerte efecto cómico por el contraste entre tan dispares cortejos, almas de difuntos frente a alimentos, símbolo del buen vivir.

\section{La descripción de los elementos}

Por lo que respecta al tratamiento de cada uno de los elementos del catálogo, en la vÉкvia, el narrador adopta dos papeles diferentes, pues o bien relata sus experiencias con aquellos que ha conocido vivos, o se convierte en un poeta genealógico cuando se refiere a los que no han formado parte de su entorno (Heubeck y Hoekstra 1989, p. 91). Ninguno de ellos sirve a Filóxeno, quien para la descripción de las viandas y rituales de banquete parece acudir ahora al catálogo de las naves. En él hay formas diferentes de presentar el contingente de tropas, según lo que interese destacar en cada momento (Kirk 1985, pp. 170-173), y el modelo que enfatiza a un héroe singular, con la descripción de sus rasgos físicos y sus habilidades sobresalientes, es el que mejor se adapta a las necesidades de nuestro poeta. Se trata de describir una

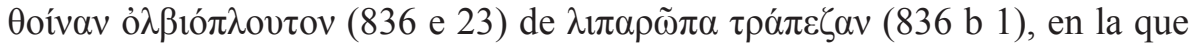
alimentos y objetos destacan por aspecto, tamaño y cantidad, sobresaliendo en excelencia entre los de su clase, igual que los héroes homéricos sobresalen entre los soldados que comandan por sus cualidades físicas extraordinarias o por alguna habilidad relacionada con su ocupación guerrera. En efecto, los

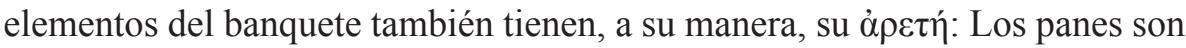

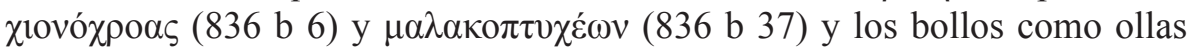

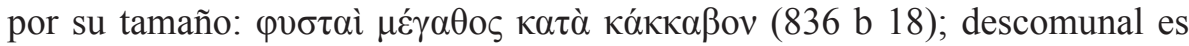

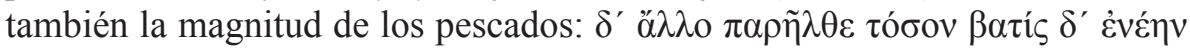

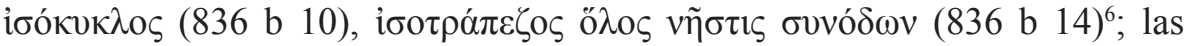

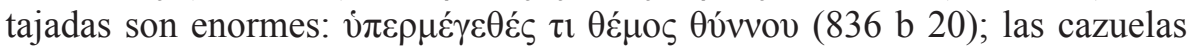

${ }^{6} \mathrm{~N} \tilde{\sigma} \sigma \tau \iota \varsigma$ es una conjetura de Schweighäuser, no incorporada por Page 1962, a la lectura $\mu v \eta ́ \sigma \tau \eta$, en la que se reconoce una corrupción. La alusión al tamaño enorme de un pescado es un tópico en estas descripciones que también encontramos en Matrón, en cuyo banquete el congrio ocupa nueve mesas (fr.1.37) y la anguila mide tres palmos y siete codos de ancho y nueve brazas de largo (fr.1.44-45). Pero el tamaño no es signo de excelencia, como advierte

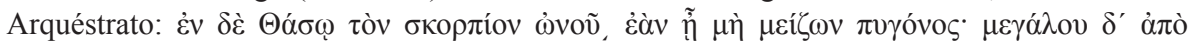
$\chi \varepsilon \bar{\rho} \rho \alpha \varsigma$ ǐ $\alpha \lambda \lambda \varepsilon$ (fr. 29). 


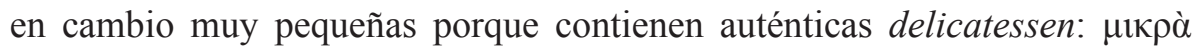

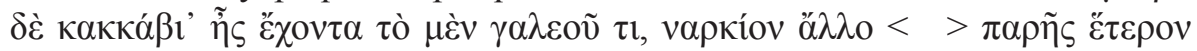

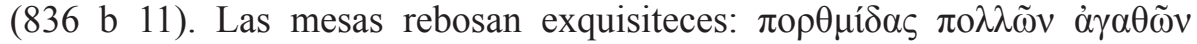

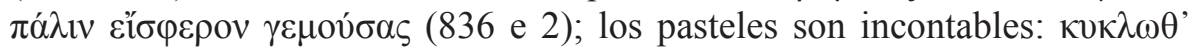

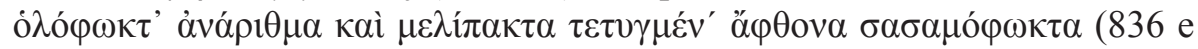
16-17). La excelencia del banquete sobrepasa lo esperable en el mundo de los mortales y por ello se enjuicia con alusiones al mundo divino, a cuya altura

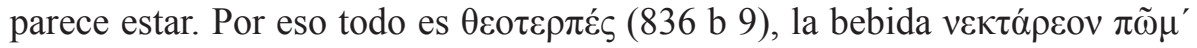

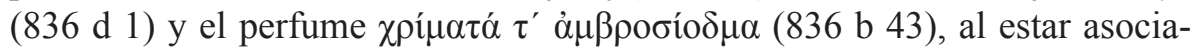
dos al néctar y la ambrosía, se equiparan a los productos que forman parte de la cotidianidad de los inmortales. Las salchichas son dignas del paladar

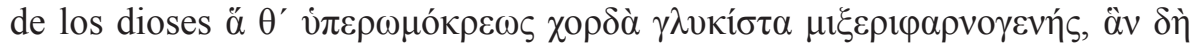

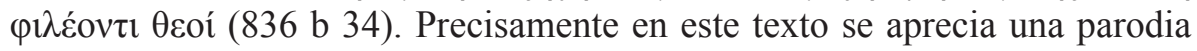
de los pasajes homéricos que expresan la preferencia de los inmortales por algún humano, manifestada en la concesión de favores o privilegios o en una especial protección:

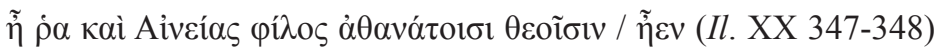

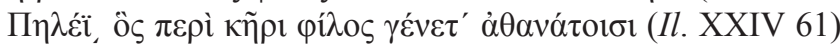

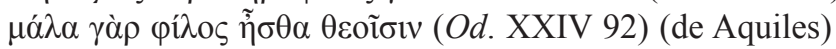

Subyace también en el texto de Filóxeno la transformación cómica de la idea expresada por el porquerizo Eumeo ante Odiseo: ov̉ $\mu \bar{\varepsilon} v \sigma \chi \varepsilon \dot{\varepsilon} \tau \lambda 1 \alpha$ है $\gamma \gamma \alpha$

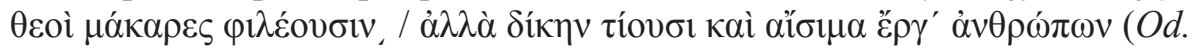
XIV 83-84). Si, según el porquero, lo que aman los dioses es la pauta que ha de determinar la conducta humana, en Filóxeno es el paradigma que sanciona el buen gusto gastronómico de los mortales. El paso de lo espiritual y sublime a lo corporal y vulgar es una forma de destronamiento del mundo heroico.

\section{Un tópico del estilo catalógico}

Es tópico omnipresente en los catálogos que el poeta manifieste su incapacidad para enumerar todos y cada uno de sus elementos por la envergadura de la materia, como forma de engrandecerla. Así lo hace Homero antes de

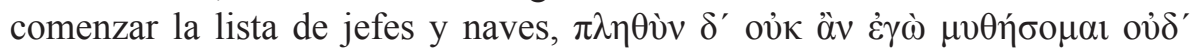

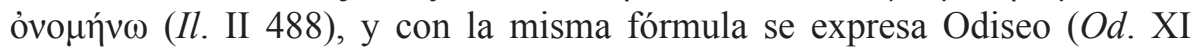
328) al final del catálogo de heroínas y Helena (Od. IV 440) antes de relatar 
a Pisístrato y Telémaco los trabajos de Odiseo en Troya. Filóxeno, haciendo uso de este tópico, que entra dentro de la hipérbole, va incluso más allá y manifiesta, no su incapacidad, sino la de cualquiera para dar cuenta exacta de

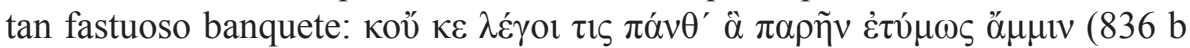
25). Recuerda esto a otras manifestaciones homéricas ajenas a los catálogos, como aquella en la que Néstor destaca la inferioridad de los hombres del

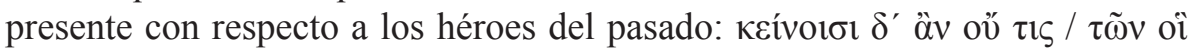

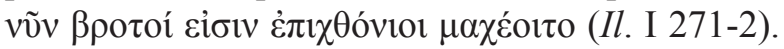

\section{Más allá de los catálogos}

Más allá de los propios de un catálogo, en el Banquete de Filóxeno se detectan otros materiales, bien sean ideas y tópicos de estilo homerizante, sin coincidencia literal con los del épico, bien sean versos concretos o partes de versos más o menos alterados.

\section{Tópicos}

Entre los tópicos hay algunos asociados a las escenas típicas de banquete. En la primera hecatombe que ofrecen los griegos (Il. I 446-71), coincidiendo con la devolución de Criseida, una vez terminado el festín y antes de la última libación ritual, el texto homérico expresa el hartazgo de los

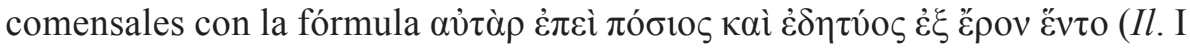
469) que se repite idéntica 20 veces más en contextos parecidos de Ilíada y Odisea $^{7}$. La misma idea, aunque sin coincidencia formal, la encontramos en Filóxeno al final de la parte principal del banquete, inmediatamente antes del lavado de manos y de la mezcla del vino que precede a los postres: ö $\tau \varepsilon$

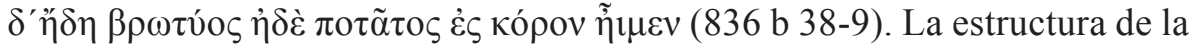
oración es la misma, pero cada término ha sido sustituido por un sinónimo. Precisamente en la ceremonia de ablución, el texto del Banquete $\dot{\alpha} \pi \alpha \lambda$ ò

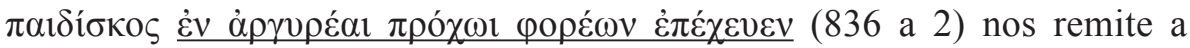

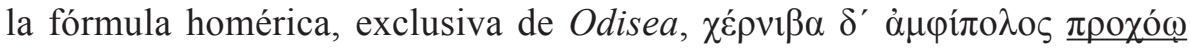

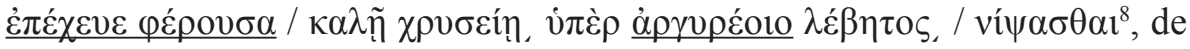

7 Il. I 469; II 432; VII 323; IX 92 y 222; XXIII 57; XXIV 628; Od. I 150; III 67 у 473; IV 68; VIII 72 y 485; XII 308; XIV 454; XV 143, 303, 501; XVI 55 y 480; XVII 99.

${ }^{8}$ Se registra 6 veces: $O d$. I 136-8; IV 52-4; VII 172-4; X 368-70; XV 135-7; XVII 91-3. 
la que parece ser una adaptación. Amén de la coincidencia de vocabulario, que hemos destacado con el subrayado, el mantenimiento de los hiatos y el empleo de la forma épica del aoristo intensifican el tono homerizante del pasaje.

En Homero hay varias referencias a la existencia de un doble lenguaje para nombrar las cosas, el propio de los dioses y el propio de los hombres. En Ilíada Egeón es Briareo para los dioses (I 403-404), y la llanura de Batiea es conocida como tumba de Mirina entre los inmortales (II 813-814) ${ }^{9}$. Esta $\delta i \omega v v \mu i ́ \alpha$ homérica, cuyo origen y función no están claras (Tsitsibakou-Vasalos 2007, pp. 89-96), es parodiada por Filóxeno, como ya señaló Eustacio (4.355.2-6), cuando indica la terminología de los dioses para designar las

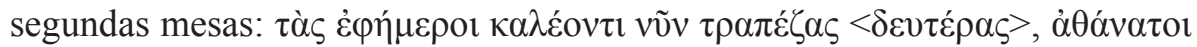

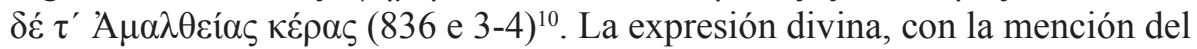
cuerno de la abundancia, incide en esa idea de opulencia tan repetida por el poeta.

\section{Literalidad homérica}

En el Banquete, además de ideas y tópicos propios del estilo homérico, Filóxeno recurre a versos o partes de versos concretos del épico, reproduciéndo-

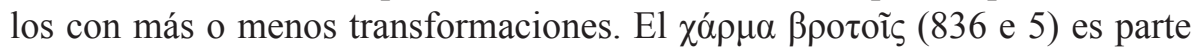

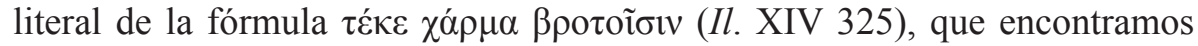
también en los Himnos Homéricos (h.Ap. 93) y con las variantes $\tau \dot{\varepsilon} \kappa \varepsilon, \theta \alpha \tilde{u} \mu \alpha$

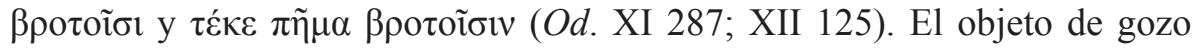
o admiración, en la épica siempre un personaje del ámbito divino, es ahora un $\alpha \varkappa \nu \nu \lambda_{o}$, , un pudin de almidón incluido con frecuencia en los catálogos de exquisiteces.

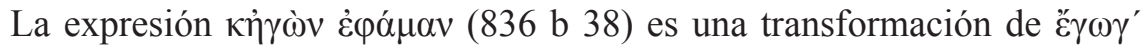

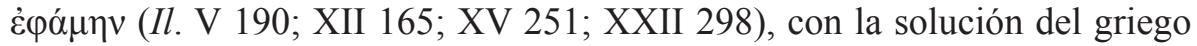
occidental en la contracción y el mantenimiento de $\bar{\alpha}$ por el color dorio de la

9 También en Il. XIV 290-1; XX 73-4; En Odisea hay dos ejemplos de terminología divina, pero sin equivalente humano (X 305; XII 61).

${ }^{10}$ Esta forma de $\delta \omega v v \mu i ́ \alpha$ tiene sus más antiguas manifestaciones en Homero, pero se encuentran testimonios de ella en la literatura posterior. V. Calderón Felices 1982 y Bader 1990 y 1991. Su adaptación al contexto de la descripción de un banquete se encuentra en el fr. 42.10-11 de Las Bodas de Hebe de Epicarmo, con el que se ha relacionado este pasaje de Filóxeno (Wilkins 2000, p. 352). 
lengua del ditirambo. En $\mu \alpha \dot{\lambda} \lambda \alpha \kappa \varepsilon v \kappa \varepsilon \chi \alpha \rho o$ ó $\mu \varepsilon \theta^{\prime}$ (836 b 23), con la forma de optativo aoristo reduplicado de la épica, subyace el homérico $\mu \varepsilon \dot{\gamma} \alpha \kappa \varepsilon v$

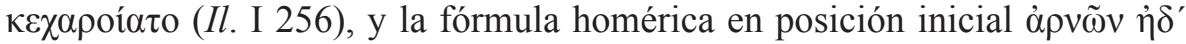

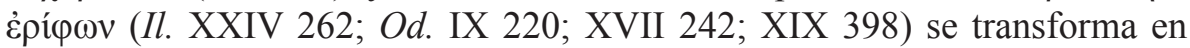

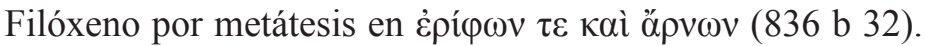

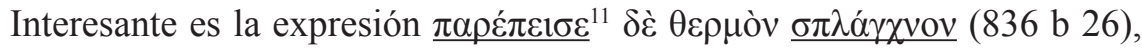

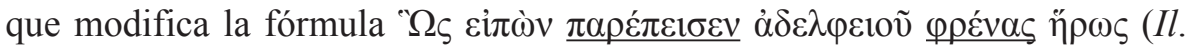
VII 120; XIII 788) u otros versos de contenido semejante, $\sigma \pi 0 v \delta \tilde{n}$

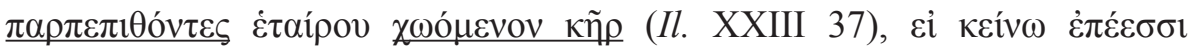

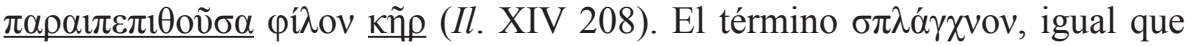
las palabras a las que sustituye, $\kappa \tilde{\eta} \rho$ у $\varphi \rho \eta ́ v$, tiene un significado anatómico, como intestinos y todos los órganos del interior del cuerpo, y un uso metafórico como sede de los afectos, que no aparece hasta los trágicos. En Homero, siempre en una escena de banquete ritual, son las «asaduras» o «entrañas», y éste es el significado que primero nos viene a la mente en este contexto gastronómico. El texto podría entenderse como «un intestino caliente (me) persuadió», considerando $\theta \varepsilon \rho \mu o ̀ v ~ \sigma \pi \lambda \alpha ́ \gamma \chi \chi \nu o v$ como sujeto. Pero la relación con el texto homérico nos sugiere su interpretación como complemento directo y nos lleva al sentido metafórico del sustantivo y del adjetivo, con lo que sería «persuadió (mi) impulsivo corazón». Nada más apropiado para un poema gastronómico que sustituir los términos homéricos por aquel que en su uso figurado significa lo mismo que ellos, pero en su primera acepción son los intestinos. El contexto anterior no nos aclara gran cosa, dado su estado de corrupción, pero sea cual sea la interpretación que conviene, es evidente que Filóxeno jugó con el texto homérico buscando con la ambigüedad un efecto cómico.

\section{Otros elementos}

Aunque dialectalmente en el Banquete predominan los rasgos dorios sobre un fondo ático, algunos elementos nos remiten a influencia de la lengua homérica. Lo más destacado es el uso optativo del aumento, aunque las proporciones están invertidas, ya que en Filóxeno son mayoritarias las

${ }^{11}$ En los manuscritos hay un $\pi \alpha \rho \varepsilon ́ \pi \varepsilon \sigma \alpha$ reconocido unánimemente como corrupto. Парє́лєıбє es una conjetura de Page 1962, considerada como probable y no incorporada al texto. 
formas con aumento $(21: 67,7 \%$, frente a $10: 32,3 \%)$, mientras que en el épico el 59,27\% (5.614) corresponde a las formas sin aumento y el 40,73 $\%$ (3.858) a las formas con aumento (Chantraine 1973, p. 484) ${ }^{12}$. La ausencia / presencia no siempre tiene justificación por comodidad métrica.

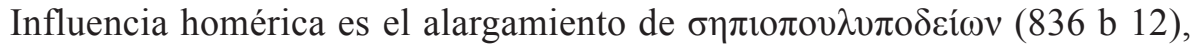

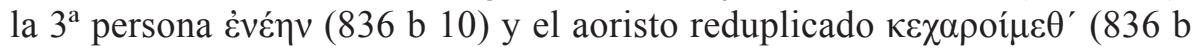
$23)$, mencionado anteriormente. Son propios de la épica algunos términos

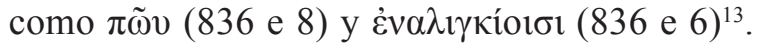

A influencia homérica hay que atribuir la presencia de algunos eolismos,

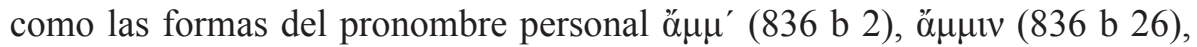
o la partícula modal $\kappa \varepsilon(836$ b.25, 35 y 37), con su variante $\kappa \varepsilon v(836$ b.23 y e.11). La ausencia de ö́v, presente en Homero como jonismo y en los poetas corales, puede explicarse como un intento deliberado de alejarse del ático (Chantraine 1963, pp. 345-350).

Lo mismo se puede decir de algunos jonismos. En la flexión nominal para el único sustantivo en genitivo plural de la primera declinación se

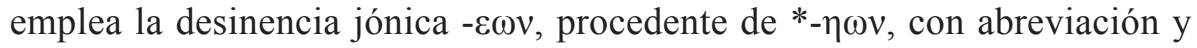
sin contracción, presente ya en Homero, aunque con mucho menor frecuencia que la variante eolia - $\bar{\alpha} \omega v$ (Chantraine 1973: 201). Son también jonismos el acusativo io $\theta \alpha \lambda \dot{\varepsilon} \alpha \varsigma$ (836 b 43) de un tema en -s, la forma $\dot{\varepsilon} \varsigma$, como

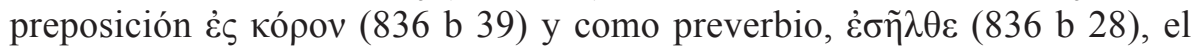

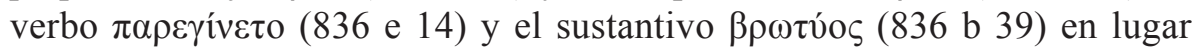
de $\beta \rho \tilde{\omega} \sigma i \varsigma^{14}$.

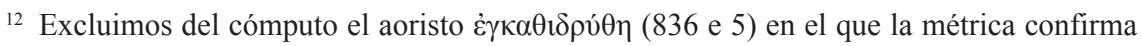
que la 1 es larga, pero la cantidad tanto puede ser imputable al aumento como a la posición ante muta cum liquida. Tampoco incluimos el imperfecto de $\varepsilon \tilde{i} \mu \mathrm{t}, \tilde{\eta} \mu \varepsilon v$ (836 b 39), y todas las demás formas del mismo por las dudas en su formación.

${ }^{13}$ Hay otros muchos términos que también están en Homero, pero no son exclusivos de la épica, sino que forman parte de la tradición poética y no podemos decir que su presencia en Filóxeno se deba a influencia homérica directa. No hacemos tampoco referencia a un buen nú-

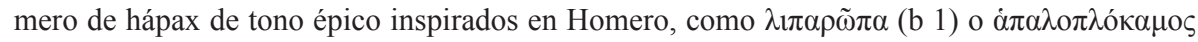
(b 12), que serán objeto de un estudio exhaustivo en otro trabajo.

${ }^{14}$ No incluimos aquí la forma sin asimilación $\mu \varepsilon ́ \gamma \alpha \theta 0 \varsigma$ (836 b 18), conservada en jonio (Lejeune 1982, p. 238), porque no aparece en Homero, quien sólo documenta la variante $\mu \varepsilon \dot{\gamma} \varepsilon \theta$ os. Hemos omitido formas presentes en Homero como eolismos o jonismos, pero que también aparecen en dorio, porque no podemos decir si está en Filóxeno por influencia del poeta épico o por el color dorio de su lengua. 


\title{
IV. ILUminANDO EL TEXTO CON HOMERO
}

El lamentable estado del texto de Filóxeno en algunos puntos ha dificultado su interpretación, pero las dudas van más allá de las posibles lagunas o corrupciones, unas veces por desconocimiento del significado de algunos términos, otras porque, aun conociéndolos, el sentido global de algunos versos resulta oscuro. Esto es lo que ocurre en e 4-10, pese a no presentar grandes dificultades textuales ni léxicas. Se trata de un pasaje inusual por la extensión con que Filóxeno se refiere a un alimento, cuando la tónica general es despachar cada manjar con una breve referencia a alguna de sus cualidades o a la forma de elaboración. La justificación de este proceder puede estar en la naturaleza de lo descrito: un $\alpha$ $\mu \nu \lambda o \varsigma$, una verdadera ex-

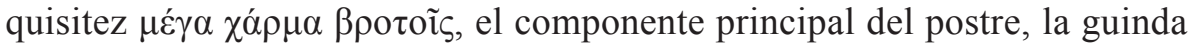
del banquete, con el cual, dada la variedad de ingredientes que admitía, los cocineros desplegaban toda su imaginación y los comensales esperaban ser sorprendidos ${ }^{15}$.

El texto, tal como lo edita Campbell 1993, p. 192, dice lo siguiente:

\author{
$\tau \alpha \tilde{i} \varsigma \delta^{\prime} \dot{\varepsilon} v \mu \varepsilon \dot{\varepsilon} \sigma \alpha \imath \sigma l v$ \\ $\dot{\varepsilon} \gamma \kappa \alpha \theta \imath \delta \rho u ́-$ \\ $\theta \eta \mu \varepsilon ́ \gamma \alpha \chi \alpha ́ \rho \mu \alpha \beta \rho \tau o i ̃ s, \lambda \varepsilon v-$

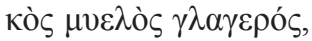

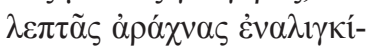

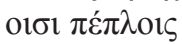

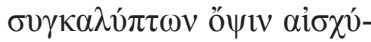

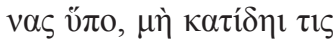

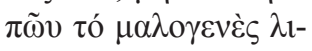

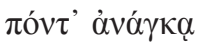

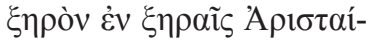

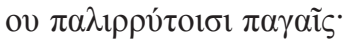

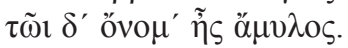

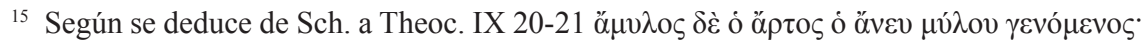

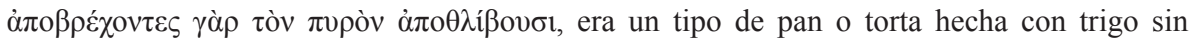
moler, humedecido y trabajado en una pasta. Se podía tomar como postre añadiéndole otros ingredientes o usarse como base de otros alimentos como tordos o liebres (Dalby 2003, p. 349), (García Soler 2001, pp. 77-78). Sobre su presencia en los catálogos de banquetes y valoración gastronómica v. Olson y Sens $(1999$, p. 78). 
A pesar de ser tan enigmático, editores y traductores no arrojan luz sobre su sentido. Dalby 1987, p. 35, se limita a dejar constancia de que el ó $\mu v \lambda o \varsigma$ es «described by Philoxenus in terms of remarkable obscurity», el propio Campbell 1993, p. 193, habla de «text and interpretation uncertain» y Edmonds 1959 , p. 359, afirma que «this sort of passage doubtless has its con-

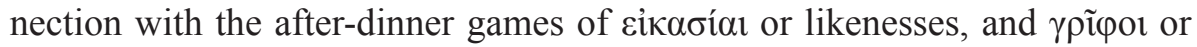
riddles», sin que pueda esgrimir ningún argumento más que la oscuridad de la expresión para los lectores modernos. Sin embargo algunas cosas están bastante claras. Uno de los ingredientes del ő́ $\mu v \lambda$ o es el designado como $\mu v \varepsilon \lambda o ́ s$. El término, que en su primera acepción significa 'médula', conoce

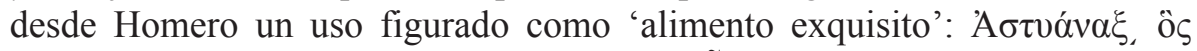

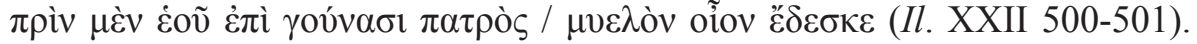
Hay acuerdo en que se refiere a algún producto lácteo, como ya indicó Meineke 1840, p. 638 , «itaque $\mu v \varepsilon \lambda$ ó $\varsigma$ non proprio sensu accepiendum, sed de lacte interpretandum», y de ahí los adjetivos que lo acompañan $\lambda \varepsilon v \kappa o ́ \varsigma \mathrm{y}$

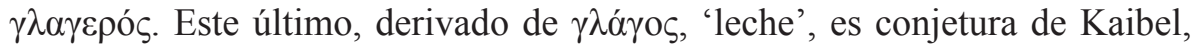
aceptada por Campbell y por Edmonds 1959, pp.356-7, corrigiendo la lectu-

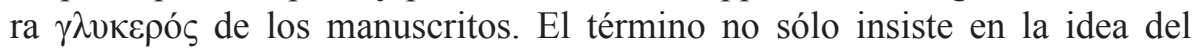
color expresado por $\lambda \varepsilon v \kappa o ́ s$, como recoge Suidas ${ }^{16}$, sino que en este contexto gastronómico no habría ningún inconveniente para suponer un significado cercano a aquél que encontramos en Opp., C. I 332, 'abundante en leche', cuando califica con él a una yegua. Sin embargo la conjetura parece innecesaria, pues además de la unánime lectura de los manuscritos, el adjetivo $\gamma \lambda v \kappa \varepsilon \rho o ́ \varsigma$ es un tradicional calificativo para «leche» que ya encontramos en

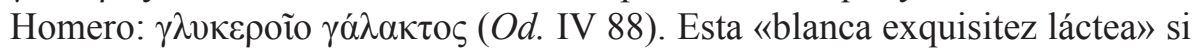
aceptamos la conjetura, o «dulce» si mantenemos la lectura de los manuscritos, ya sea queso fresco o la cuajada que se hacía calentando la leche sobre ceniza (García Soler 2001, pp. 272-273), bien puede estar elaborada con calostro, muy sabroso y apreciado en la antigüedad.

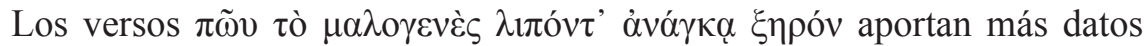
sobre la naturaleza y cantidad del producto. El término épico $\pi \tilde{\omega} v$ designa, ya desde Homero, al rebaño de ovejas, $\pi \omega ́ \varepsilon \alpha$ oĩ̃v (Il. XI 678) o tal vez de

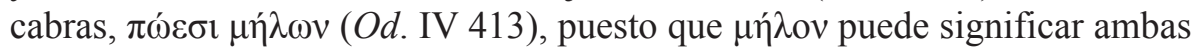

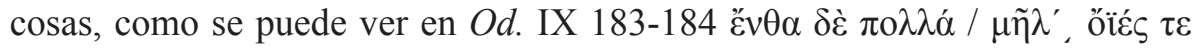

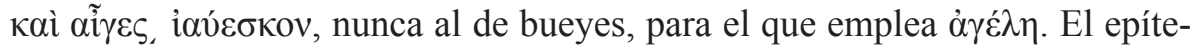

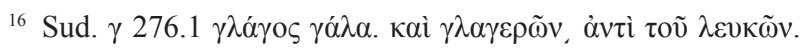


to $\mu \alpha \lambda o \gamma \varepsilon v i ́ s$, un hápax al estilo de los muchos que existen desde Homero para indicar origen o filiación, no añade especificación alguna ${ }^{17}$. Este rebaño además se ha quedado «seco por necesidad», lo que quiere decir que para elaborar el postre se ha necesitado toda la leche que sus ovejas podían dar en ese momento, en una evidente hipérbole, que no hace más que incidir en la idea de abundancia que preside todo el banquete.

La mención de Aristeo ilumina el sentido de los versos siguientes, por ser

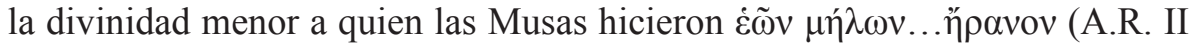

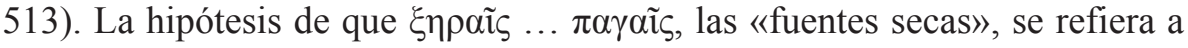
las ubres de las ovejas, como recoge Dalby en su traducción (1987, p. 31), parece acertada, a pesar de las dudas de Campbell 1993, p. 193. Se ha pasa-

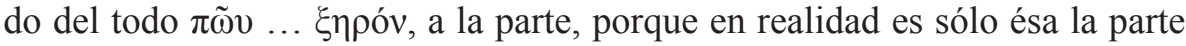
de la anatomía de las ovejas afectada por la sequía, repitiendo la misma idea, que además se destaca con el refuerzo expresivo de la paronomasia $\xi \eta \rho \grave{v} \dot{\varepsilon} v$

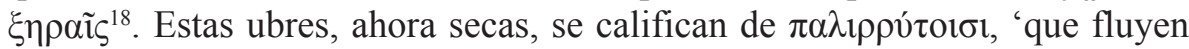
de nuevo' y este adjetivo, documentado únicamente aquí y en Sófocles $(E l$.

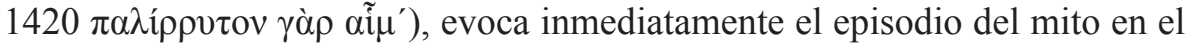
que Aristeo soluciona la sequía de las Cícladas, con sus plegarias y sacrificios a Zeus Icmeo. Éste, conmovido, hace soplar durante 40 días los vientos etesios que traen frescor y humedad, haciendo brotar de nuevo las fuentes ${ }^{19}$. Igual que aquéllas, estas 'fuentes' ovejunas también volverán a manar para abastecer otros banquetes. Explicado el texto así, las correcciones propuestas

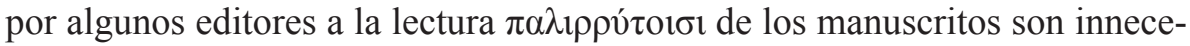
sarias $^{20}$.

Pero nombrar a Aristeo en un contexto culinario también nos lleva inmediatamente a recordar otra de sus actividades campesinas, la apicultura, el arte en el que fue instruido por las Musas ${ }^{21}$, y el producto obtenido de esta dedicación, la miel, omnipresente en la gastronomía griega antigua y moderna, muchas veces en perfecto maridaje con los lácteos, como vemos en otros

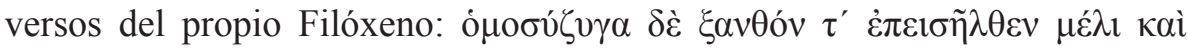

${ }^{17}$ En $\mu \tilde{\eta} \lambda o v$ la $\overline{\mathrm{e}}$ es originaria y no procedente de $\overline{\mathrm{a}}$. Por la forma $\mu \alpha \lambda \mathrm{\lambda}-$ del compuesto es un hiperdorismo.

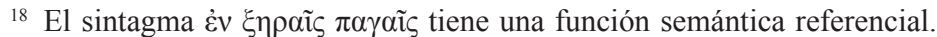

19 Esta historia está desarrollada sobre todo en A.R. II 516-527 y D.S. IV 82.1-3

${ }^{20}$ En la edición de Page 1962 se lee $\mu \varepsilon \lambda \iota \rho \rho v ́ \tau o t \sigma ı$, conjetura de Meineke 1840, p. 640,

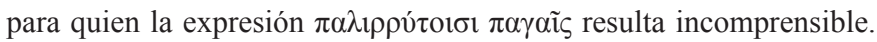

${ }^{21}$ Sobre Aristeo y la apicultura cf. Nonn., D. V 242-257. 


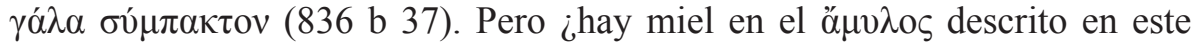
pasaje? A nuestro modo de entender sí y la referencia a ella está en las siguientes palabras (836 e 6), que comprenderemos mejor a través de Homero:

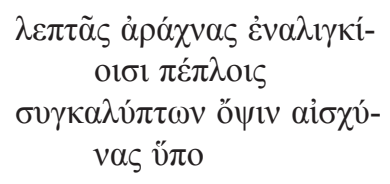

La respuesta al enigma de qué son estos metafóricos peplos que ocultan la «blanca exquisitez láctea»o «dulce» y qué sentido tiene hablar del pudor de la cuajada, la encontramos en la expresión $\lambda \varepsilon \pi \tau \tilde{\alpha} \varsigma$ ả $\rho \alpha ́ \chi v \alpha \varsigma$. Sea lo que sea, la apariencia del producto es la de una sutil telaraña. Si tenemos en cuenta la evocación de leche y miel que suscita la mención de Aristeo y la frecuencia con la que ambos productos se combinan, no parece descabellado suponer

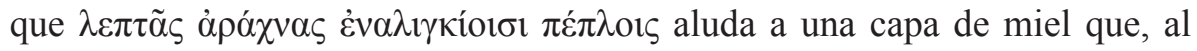
escurrir, ha formado hilos finísimos, porque, según es costumbre, se ha echado caliente sobre la cuajada en el momento de servirla (García Soler 2001, p. 377).

Explicado esto, la cuestión del pudor se resuelve acudiendo a Homero,

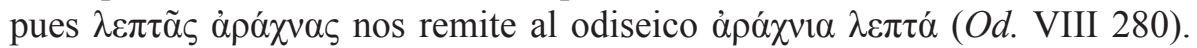
Este sintagma forma parte del relato de los amores de Ares y Afrodita (Od. VIII 266-369), un episodio único en el poeta épico por su contenido sexual, que, trasladándonos al ámbito de la vida privada del Olimpo, nos muestra un adulterio $\lambda \alpha \dot{\alpha} \theta \rho n$ en el que el pudor está totalmente ausente. Filóxeno hace una transformación paródica del pasaje, sustituyendo a los protagonistas y alterando su carácter, pero dejando como pista para su interpretación la mención de la sutil telaraña. El lugar de Afrodita, la más bella del Olimpo, lo ocupa ahora el ámylos, el manjar más exquisito de las segundas mesas. La telaraña, invisible incluso para los inmortales, fabricada por Hefesto para poner en evidencia el impúdico comportamiento de los amantes y dejar sus cuerpos desnudos a la vista de todos, sirve ahora para salvaguardar el pudor de la blanca exquisitez láctea evitando que alguien la vea. Interpretado el texto de Filóxeno como parodia del episodio homérico, hasta podemos encontrar en el épico una justificación añadida para la mención de Aristeo. En efecto no podemos olvidar que, además de ser hijo de Apolo, su nombre se usa también como epíteto de Apolo y este dios juega un papel importante en el episodio erótico, por sus jocosos comentarios de la situación. 
Esta relación transtextual con Homero arroja luz sobre este texto para el que proponemos la siguiente traducción:

«En medio de ellas estaba colocada, gran delicia para los mortales, una blanca exquisitez láctea, que con peplos semejantes a una sutil telaraña ocultaba el rostro por pudor, para que nadie viese que había dejado el rebaño de ovejil linaje seco por necesidad, en las secas fuentes de Aristeo que manan de nuevo. Su nombre era ámylos».

\section{Conclusiones}

El estudio del Banquete de Filóxeno nos descubre que el estilo ditirámbico que caracteriza la obra está entreverado de material homérico de distinta procedencia y naturaleza, en cantidad notablemente menor que en Matrón.

Al tratarse de un catálogo gastronómico, el autor acude, como era de esperar, a los dos principales catálogos homéricos y también a las escenas de sacrificios y banquetes rituales cuya forma de expresión imita. Pero además se detectan materiales tomados de pasajes de otra naturaleza, tanto de Ilíada como de Odisea.

La relación con el texto homérico se concreta en el uso de tópicos y de fórmulas o citas textuales con más o menos transformaciones.

A nivel lingüístico, sobre una base doria, propia del ditirambo, el texto se salpica de eolismos y jonismos, así como de rasgos gramaticales propios de la lengua homérica. A esto hay que sumar el uso de vocabulario específico de la epopeya.

La relación textual con el texto homérico permite interpretar pasajes oscuros, así como detectar recursos de humor que de otro modo pasan desapercibidos.

\section{BIBLIOGRAFÍA}

Bader, F. 1990: «Autobiographie et héritage dans la langue des dieux: d'Homère a Hésiode et Pindare I», REG 103, pp. 383-408.

Bader, F. 1991: «Autobiographie et héritage dans la langue des dieux: d'Homère a Hésiode et Pindare II», REG 104, pp. 330-345.

Calderón Felices, E. 1982: «Lengua de los dioses / lengua de los hombres», Faventia 4/1, pp. 5-33. 
Campbell, D. A. 1993: Greek Lyric, V. The New School of Poetry and Anonymus Songs and Hymns, Cambridge-Londres.

Chantraine, P. 1963: Grammaire Homérique. T. I I Syntaxe, París.

Chantraine, P. 1973: Grammaire Homérique. T. I Phonétique et Morphologie, París.

Dalby, A. 1987: «The Banquet of Philoxenus: A new translation with culinary notes», Petits propos culinaires 26, pp. 28-36.

Dalby, A. 1994: Unequal feasts. Food and its social context in early Greece, Londres. Tesis doctoral.

Dalby, A. 2003: Food in the ancient world. From A to Z, Londres-Nueva York.

Degani, E. 1998: «Filosseno de Leucade e Platone Comico», Eikasmos 9, pp. 81-99.

Dickey, E. 1996: Greek Forms of Address. From Herodotus to Lucian, Oxford.

Edmonds, J. M. 1959: Lyra Graeca, vol. III, Londres.

García Soler, Ma. J. 2001: El arte de comer en la antigua Grecia, Madrid.

Genette, G. 1989: Palimpsestos. La literatura en segundo grado, Madrid.

Heubeck, A. y Hoekstra, A. 1989: A Commentary On Homer's Odyssey, vol. II, books IX-XVI, Oxford.

Kirk, G. S. 1985: The Iliad: A Commentary, vol. I: books 1-4, Cambridge.

Lejeune, M. 1982: Phonétique historique du mycénien et du grec ancien, París.

Meineke, A. 1840: Fragmenta poetarum comoediae mediae, vol. III, Berlín.

Olson, D. S. y Sens, A. 1999: Matro of Pitane and the Tradition of Epic parody in Fourth Century BCE, Atlanta.

Olson, D. S. y Sens, A. 2000: Archestratos of Gela. Greek Culture and Cuisine in the Fourth Century BC, Oxford.

Page, D. L. 1962: Poetae melici graeci, Londres.

Salvioni, L. 1979-80: «Procedimenti parodici in Matrone», Bolletino dell' Istituto di Filologia Greca dell' Università di Padova 5, pp. 21-29.

Sutton, D. F 1989: Dithyrambographi Graeci, Hildesheim.

Tsitsibakou-Vasalos, E. 2007: Ancient Poetic Etymology. The Pelopids: Fathers and Sons, Stuttgart.

Wilkins, J. 2000: The Boastful Chef. The Discourse of Food in Ancient Greek Comedy, Oxford.

Wilkins, J. y Hill, S. 2011: Archestratus: Fragments from the Life of Luxury. Revised edition (first published 1994), Totnes.

Fecha de recepción de la primera versión del artículo: 22/04/2013

Fecha de aceptación: 26/07/2013

Fecha de recepción de la versión definitiva: 30/07/2013 